\title{
Effect of transdermal nitroglycerin patch on severe preeclamptic women with abnormal Doppler indices
}

\author{
El-Sayed S. El-Ebshehy*, Ahmed M. Hagras, Amr T. Elbadry, Ahmed M. Awara
}

Department of Obstetrics and Gynecology, Tanta University, Tanta, Egypt

Received: 20 November 2018

Accepted: 29 December 2018

\section{*Correspondence:}

Dr. El-Sayed S. El-Ebshehy,

E-mail: dr.elsayed.samy@ gmail.com

Copyright: ( ) the author(s), publisher and licensee Medip Academy. This is an open-access article distributed under the terms of the Creative Commons Attribution Non-Commercial License, which permits unrestricted non-commercial use, distribution, and reproduction in any medium, provided the original work is properly cited.

\begin{abstract}
Background: The aim is to evaluate the effect of maternal transdermal nitro-glycerine patch administration on blood flow resistance on maternal uterine artery, fetal umbilical and middle cerebral arteries in patients with severe preeclampsia in early gestational age (24 weeks to 33 weeks) associated with abnormal Doppler indices (placental insufficiency) and also its effect on maternal mean arterial blood pressure.

Methods: This is a prospective interventional clinical trial conducted on (50) pregnant women with singleton pregnancy diagnosed with severe pre-eclampsia admitted in high-risk pregnancy unit at the Department of Obstetrics in Tanta University Hospitals, A 50-mg transdermal GTN patch (Novartis Pharma) was applied to the abdominal skin, releasing nitroglycerin at a rate of $0.4 \mathrm{mg} / \mathrm{h}$. Doppler ultrasonography and measurement of maternal blood pressure were performed before application of transdermal GTN patch, after 4 hours of application, after 24 hours and after 48 hours.

Results: the application of a 50-mg transdermal GTN patch to the maternal abdomen was associated with a significant decline in the PI of the uteroplacental and fetoplacental blood flow. No change was observed in the PI of the cerebral circulation. And also, there was a significant decrease in maternal blood pressure (MAP).

Conclusions: Nitroderm patch (nitric oxide donors) may be used as initial therapy in cases of severe preeclampsia complicated by placental insufficiency in the form of abnormal Doppler indices.
\end{abstract}

Keywords: Doppler ultrasound, Severe preeclampsia, Nitric oxide, Nitroderm patch

\section{INTRODUCTION}

Pre-eclampsia is one of the most serious pregnancy complications and, in its severe form, is one of the main causes of maternal and perinatal morbidity and mortality. Preeclampsia and eclampsia are among the three main causes of maternal mortality worldwide, affecting approximately $4.6 \%$ and $1.4 \%$ of all births, respectively. Preeclampsia is best described as a pregnancy-specific syndrome that can affect virtually every organ system although often chiefly includes the development of newonset hypertension in the second half of pregnancy accompanied by new-onset proteinuria. The appearance of proteinuria remains an important diagnostic criterion. Thus, proteinuria is an objective marker and reflects the system-wide endothelial leak, which characterizes the preeclampsia syndrome. ${ }^{1}$

The pathophysiology of pre-eclampsia has not yet been clearly established. But there is a consensus that endothelial dysfunction plays an important role in the pathogenesis of preeclampsia., ${ }^{2,3}$ Endothelial dysfunction can be broadly defined as an imbalance between vasodilator and vasoconstrictor substances produced from the endothelium. ${ }^{3}$ Among many endothelium-derived vasoactive factors, nitric oxide (NO) is a critical vessel- 
relaxing molecule. ${ }^{4}$ As the key synthesis enzymes of NO, endothelial nitric oxide synthase enzyme (eNOS) is the focus of endothelial dysfunction in preeclampsia. ${ }^{5,6}$ Recent studies have shown that eNOS levels are significantly decreased in both preeclamptic maternal blood and placenta, indicating the NO system is damaged in preeclampsia. ${ }^{7,8}$

Nitric Oxide, this potent vasodilator is synthesized from 1-arginine by endothelial cells. ${ }^{9}$ The effects of nitric oxide production in preeclampsia are unclear. It appears that the syndrome is associated with decreased endothelial nitric oxide synthase expression, thus increasing nitric oxide inactivation. ${ }^{5,6}$ Glyceryl trinitrate (nitroglycerin, GTN) produces nitric oxide through a biotransformation pathway. ${ }^{10}$

Doppler velocimetry is a non-invasive method used to evaluate blood follow resistance in utero placental circulation and fetoplacental circulation to predict perinatal outcome and help in appropriate intervention in pregnancies complicated with preeclampsia. ${ }^{11}$ The aim of this study is to evaluate the effect of maternal transdermal nitroglycerin administration on blood flow resistance in uterine artery, fetal umbilical and middle cerebral arteries in patients with severe pre-eclampsia with abnormal Doppler indices (placental insufficiency) and maternal mean arterial blood pressure.

\section{METHODS}

This is a prospective study conducted on (50) pregnant women with singleton pregnancy diagnosed with severe pre-eclampsia admitted in high risk pregnancy unit at the Department of Obstetrics and Gynecology in Tanta University Hospitals from January 2017 to June 2018.

\section{Inclusion criteria}

- Age of mother from 20 to 30 years.

- Singleton pregnancy.

- Gestational age from 24 weeks to 32 weeks and 6 days. All patients should have accurate dating with a gestational age based on the last menstrual period that should be validated with a US examination, during which crown-rump length is measured between 11 and 14 weeks; if that is not possible, biparietal diameter measurement is used between 14 and 22 weeks.

- $\quad$ Blood pressure $\geq 160 \mathrm{~mm} \mathrm{Hg}$ systolic or $\geq 110 \mathrm{~mm}$ $\mathrm{Hg}$ diastolic on two separate occasions at least 6 hours apart.

- Proteinuria defined by the excretion of $300 \mathrm{mg}$ or more of protein in a 24-hour urine collection. Or a protein/creatinine ratio of at least $0.3 \mathrm{mg} / \mathrm{dl}$.

- Abnormal uterine and/or umbilical arteries Doppler with correlation to the gestational age. (Uterine artery Doppler velocity waveforms were considered abnormal when the mean RI between the left and right uterine arteries was $\geq 0.58 .{ }^{12}$ Umbilical artery
Doppler velocity waveforms were considered abnormal when the RI was greater than the 95th percentile for gestational age). ${ }^{13}$

\section{Exclusion criteria}

- $\quad$ Preterm premature rupture of membrane.

- Clinical diagnosis of placental abruption.

- Chronic oligohydarmnios.

- Reversed flow of the umbilical artery waveform.

- The use of any antihypertensive medication other than alpha-methyl dopa or magnesium sulfate

- Eclampsia.

- Systemic diseases including thyroid dysfunction, DM, renal, chronic hypertension, and coronary diseases.

- Intra uterine fetal death or any congenital anomalies

- Any maternal contraindication for the use of nitroglycerine as hypotension, and Intolerance to nitroglycerine.

\section{Methods}

During expectant management, maternal and fetal conditions should be frequently monitored as follows:

\section{Maternal assessment}

- Vital signs, fluid intake, and urine output should be monitored at least every 8 hours. Symptoms of severe preeclampsia (headaches, visual changes, retrosternal pain or pressure, shortness of breath, nausea and vomiting, and epigastric pain) should be monitored at least every 8 hours

- Presence of contractions, rupture of membranes, abdominal pain, or bleeding should be monitored at least every 8 hours

- Laboratory testing (CBC and assessment of platelet count, liver enzyme, and serum creatinine levels) should be performed daily. (These tests can then be spaced to every other day if they remain stable and the patient remains asymptomatic.)

\section{Fetal assessment}

- Kick count and NST with uterine contraction monitored daily

- Biophysical profile.

Color Doppler velocimetry was performed on a Samsung H60 USS-H60NF 4K/WR (SAMSUNG MEDISON CO., LTD) ultrasound scanner, using a $3.75-\mathrm{MHz}$ convex transducer. Patients were examined in the semi-Fowler position, during a period of absent fetal movements and breathing. A minimum of six uniform Doppler waveforms were measured. The Doppler sample gate was adjusted according to vessel diameter, and the insonation angle was maintained as close to zero as possible. Pulsatility index (PI), RI and S/D were automatically 
calculated by the equipment. Measurements were performed on the ascending branches of the right and left uterine arteries, at the point of apparent crossing with the external iliac arteries.

The umbilical artery was evaluated at the free loop, near the placental insertion, while the middle cerebral artery was evaluated in an axial section of the brain at the level of the circle of Willis. Each sequence of measurements was performed in triplicate during each examination, and the results were averaged.

A 50-mg transdermal GTN patch (Novartis Pharma AG, Stein, Switzerland) was applied to the abdominal skin, releasing nitroglycerin at a rate of $0.4 \mathrm{mg} / \mathrm{h}$. The dosage was kept constant during the study.

The patch was applied for 16 hours then removed for 8 hours to avoid tolerance to GTN. Doppler ultrasonography and maternal blood pressure were performed before application of transdermal GTN patch, after 4 hours of application, after 24 hours and after 48 hours.

Measurement of arterial pressure was performed using a sphygmomanometer (mercury column) every $4 \mathrm{~h}$, always on the left arm, with the patient seated and with the fourth Korotkoff sound used to determine diastolic blood pressure. Mean arterial blood pressure (MAP) (diastolic pressure $+1 / 3$ [systolic pressure-diastolic pressure]) was used for comparisons.

The main outcome was the effect of transdermal nitroglycerin application on the PI values of the uterine artery, fetal umbilical and middle cerebral arteries, when compared with the values obtained before applying the patch.

Secondary outcomes will be the effect of GTN therapy on maternal blood pressure and the side effects of GTN therapy.

\section{Potential risks}

- No potential risks are considered by using Color Doppler.

- Side effects of nitroglycerine include: hypotension and headache.

- Any unexpected risks appeared during the course of the research will be cleared to participants and the ethical committee on time.

\section{Ethical committee}

- $\quad$ The study was started after medical ethical committee approval.

- Written consent from all included patients.

- $\quad$ All included patient knows about the aim of present study, risk factors, possible complications and risk of failure.

\section{Provision of privacy}

There are adequate provisions to maintain privacy of participants and confidentiality of the data, the patient name was replaced by serial number and her address kept confidential. There is no conflict of interest. Authors don't receive any fund from any institute. Authors didn't give any compensation to the participant. Authors didn't represent any risk to the environment. Authors took verbal and written consent from the participants. The work is stopped if the patient refuses to continue. No differentiation between patients according to religion and race.

\section{RESULTS}

This study was carried on (50) pregnant women with severe preeclampsia (demographic and characteristic data of studied women as regard, maternal age $(23 \pm 5.7)$ years, $66 \%$ of them nulliparous, gestational age $(28.5 \pm 1.3)$

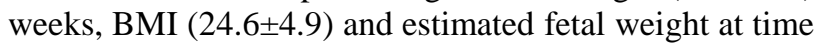
of admission $(987 \pm 254)$ gm. 9 patients of the studied women show history of preeclampsia (18\%)

Among the 50 patients who were initially enrolled, seven could not follow the study protocol and were excluded from the final analysis: three patients had severe headaches requiring GTN patch removal, two patients with clinical symptoms and signs suggestive of imminent eclampsia necessitated pregnancy termination. And two patients presented by uncontrollable blood pressure requiring intravenous administration of antihypertensive drugs.

Headache was the most common side effect, occurring in $35(70 \%)$ of 50 patients. However, in only three $(6 \%)$ cases was the pain severe enough to require interruption of the GTN treatment. The other patients had symptomatic relief with administration of analgesics and adaptation to the medication. Three $(6 \%)$ cases showed hyperemia where the patch was applied, but there was no need to interrupt the study.

Uterine artery PI showed a significant decrease after 4 hours of patch application as it was $(1.98 \pm 0.09)$ before patch application and become $(1.80 \pm 0.14)$ after 4 hours of patch application ( $\mathrm{P} 1<0.001)$ and continued to decrease to become $(1.57 \pm 0.09)$ after 24 hours (P2 $<0.001)$ and to $(1.51 \pm 0.05)$ after 48 hours $(\mathrm{P} 3<0.001)$ with the usage of the patch. And when comparing the uterine artery PI after 48 hours of patch application and after 4 hours from its application there is a significant decrease in PI $(\mathrm{P} 4<0.035)$.

From table 1 authors conclude that nitric oxide donors improve uterine blood flow, so the patch improves uteroplacental circulation in cases of severe preeclampsia with placental insufficiency. Umbilical artery PI showed a significant decrease after 4 hours of patch application as it was $(1.81 \pm 0.2)$ before patch application and become 
(1.62 \pm 0.18$)$ after 4 hours of patch application $(\mathrm{P} 1<0.05)$ and continued to decrease to become $(1.40 \pm 0.13)$ after 24 hours $(\mathrm{P} 2<0.001)$ and to $(1.38 \pm 0.14)$ after 48 hours $(\mathrm{P} 3$ $<0.001)$ with the usage of the patch. And when comparing the Umbilical artery PI after 48 hours of patch application and after 4 hours from its application there is a significant decrease in PI (P4 <0.04). In table 2 authors conclude that nitric oxide donors improve placental blood flow, so the patch improve feto-placental circulation in cases of severe preeclampsia with placental insufficiency. Fetal middle cerebral artery PI measurements before, 4 hours, 24 hours and 48 hours with the usage of nitroglycerine patch shows no significant difference on the MCA resistive index $(\mathrm{P} 1<0.477, \mathrm{P} 2<0.522, \mathrm{P} 3$ $<0.588$, P4 $<0.485)$. In Table 3 authors conclude that nitric oxide donors have no effect of fetal cerebral circulation. Systolic blood pressure decreased significantly after 4 hours from GTN patch application from $(169 \pm 7.5 \mathrm{mmHg})$ to become $(150 \pm 7.25 \mathrm{mmHg})$ with (P1a <0.01). And diastolic blood pressure decreased significantly from $(114 \pm 4.25 \mathrm{mmHg})$ to become $(94 \pm 5.10 \mathrm{mmHg})$ with $(\mathrm{P} 1 \mathrm{~b}<0.05)$. And mean arterial blood pressure decreased significantly from $(132 \pm 5.35 \mathrm{mmHg})$ to become $(113 \pm 4.3 \mathrm{mmHg})$ with $(\mathrm{P} 1 \mathrm{c}$ $<0.05)$

Table 1: Pulsatility index of uterine artery before, 4 hours after application of nitroglycerine patch, 24 hours after and 48 hours on 43 patients with severe preeclampsia.

\begin{tabular}{|c|c|c|c|c|c|}
\hline \multirow{2}{*}{ Uterine artery PI } & \multicolumn{4}{|c|}{ Patch application } & p \\
\hline & Before & 4 hours after & 24 hours after & 48 hours after & \multirow{4}{*}{$<0.001 *$} \\
\hline $\operatorname{Min}-\operatorname{Max}$ & $1.83-2.12$ & $1.73-195$ & $1.69-1.80$ & $1.66-1.78$ & \\
\hline Mean \pm SD & $1.98 \pm 0.09$ & $1.80 \pm 0.14$ & $1.57 \pm 0.09$ & $1.51 \pm 0.05$ & \\
\hline Sig bet indices & \multicolumn{4}{|c|}{$\mathrm{P} 1<0.001 *, \mathrm{P} 2<0.001 *, \mathrm{P} 3<0.001 *, \mathrm{P} 4<0.035 *$} & \\
\hline
\end{tabular}

Table 2: Pulsatility index of umbilical artery before, 4 hours after application of nitro-glycerine patch, 24 hours after and 48 hours on 43 patients with severe preeclampsia.

\begin{tabular}{|c|c|c|c|c|c|}
\hline \multirow{2}{*}{ Umbilical artery PI } & \multicolumn{4}{|c|}{ Patch application } & \multirow[t]{2}{*}{ p } \\
\hline & Before & 4 hours after & 24 hours after & 48 hours after & \\
\hline Min - Max & $1.55-1.90$ & $1.56-1.78$ & $1.32-1.53$ & $1.21-1.48$ & \multirow[t]{2}{*}{$<0.001 *$} \\
\hline Mean \pm SD & $1.81 \pm 0.2$ & $1.62 \pm 0.18$ & $1.40 \pm 0.13$ & $1.38 \pm 0.14$ & \\
\hline Sig bet indices & \multicolumn{4}{|c|}{$\mathrm{P}_{1}<0.05 *, \mathrm{P}_{2}<0.001 *, \mathrm{P}_{3}<0.001 *, \mathrm{P}_{4}<0.04 *$} & \\
\hline
\end{tabular}

Table 3: Pulsatility index of middle cerebral artery before, 4 hours after application of nitroglycerine patch, after 24 hours and after 48 hours on 43 patients with severe preeclampsia.

\begin{tabular}{|c|c|c|c|c|c|}
\hline \multirow{2}{*}{ MCA artery PI } & \multicolumn{4}{|c|}{ Patch application } & p \\
\hline & Before & 4 hours after & 24 hours after & 48 hours after & \multirow{4}{*}{$<0.653$} \\
\hline Min-Max & $1.51-1.82$ & $1.52-1.79$ & $1.53-1.82$ & $1.49-1.83$ & \\
\hline Mean \pm SD & $1.60 \pm 0.1$ & $1.57 \pm 0.17$ & $1.58 \pm 0.26$ & $1.59 \pm 0.05$ & \\
\hline Sig bet indices & \multicolumn{4}{|c|}{$\mathrm{P}_{1}<0.477, \mathrm{P}_{2}<0.522, \mathrm{P}_{3}<0.588, \mathrm{P}_{4}<0.485$} & \\
\hline
\end{tabular}

When comparing the blood pressure before and after 48 hours with the application of nitroglycerine patch; The mean arterial blood pressure (MAP) decreased significantly with GTN use from $(132 \pm 5.35 \mathrm{mmHg})$ to $(115 \pm 6.15 \mathrm{mmHg})(\mathrm{Pc}<0.05)$. This was also evident from the decrease of systolic arterial pressure from
$(169 \pm 7.5 \mathrm{mmHg})$ to $(140 \pm 7.5 \mathrm{mmHg})(\mathrm{Pa}<0.01)$, and of diastolic arterial blood pressure from $(114 \pm 4.25 \mathrm{mmHg})$ to $(95 \pm 5.05) \mathrm{mmHg}(\mathrm{Pb}<0.05)$. From Table 4 authors can conclude that application of GTN patch in cases of severe preeclampsia is significantly effective in controlling blood pressure. 
Table 4: Effect of nitroglycerine patch on systolic, diastolic and mean arterial blood pressure before, after 4 hours, after 24 hours and after 48 hours on 43 patients with severe preeclampsia.

\begin{tabular}{|c|c|c|c|c|c|}
\hline & \multicolumn{4}{|c|}{ Patch application } & \multirow[t]{3}{*}{ p } \\
\hline & Before & 4 hours after & 24 hours after & 48 hours after & \\
\hline \multicolumn{5}{|l|}{ Systolic } & \\
\hline Min-Max & $160-190$ & $140-165$ & $145-160$ & $140-165$ & \multirow{3}{*}{$<0.01 * \mathrm{a}$} \\
\hline Mean \pm SD & $169 \pm 7.5$ & $150 \pm 7.25$ & $145 \pm 8.25$ & $140 \pm 7.5$ & \\
\hline Sig bet indices & \multicolumn{4}{|c|}{$\mathrm{P} 1 \mathrm{a}<0.01 *, \mathrm{P} 2 \mathrm{a}<0.01 *, \mathrm{P} 3 \mathrm{a}<0.01 *, \mathrm{P} 4 \mathrm{a}<0.305$} & \\
\hline \multicolumn{5}{|l|}{ Diastolic } & \multirow{4}{*}{$<0.05 * \mathrm{~b}$} \\
\hline Min-Max & $110-120$ & $90-100$ & $85-105$ & $90-100$ & \\
\hline Mean \pm SD & $114 \pm 4.25$ & $94 \pm 5.10$ & $92 \pm 7.25$ & $95 \pm 5.05$ & \\
\hline Sig bet indices & \multicolumn{4}{|c|}{$\mathrm{P} 1 \mathrm{~b}<0.05 *, \mathrm{P} 2 \mathrm{~b}<0.045 *, \mathrm{P} 3 \mathrm{~b}<0.05 *, \mathrm{P} 4 \mathrm{~b}<0.278$} & \\
\hline \multicolumn{5}{|l|}{ MAP } & \multirow{4}{*}{$<0.05 * \mathrm{c}$} \\
\hline Min-Max & $127-146$ & $110-120$ & $105-120$ & $105-125$ & \\
\hline Mean \pm SD & $132 \pm 5.35$ & $113 \pm 4.3$ & $112 \pm 5.05$ & $115 \pm 6.15$ & \\
\hline Sig bet indices & \multicolumn{4}{|c|}{$\mathrm{P} 1 \mathrm{c}<0.05 *, \mathrm{P} 2 \mathrm{c}<0.031 *, \mathrm{P} 3 \mathrm{c}<0.05 *, \mathrm{P} 4 \mathrm{c}<0.342$} & \\
\hline
\end{tabular}

\section{DISCUSSION}

In present study authors showed that the application of a 50-mg transdermal GTN patch to the maternal abdomen was associated with a significant decline in the PI of the uteroplacental (uterine arteries) and fetoplacental (umbilical arteries) blood flow. No change was observed in the PI of the cerebral circulation (middle cerebral artery). And also, there was a significant decrease of maternal blood pressure (MAP).

Various studies report the effects of NO donors on fetal and uterine blood flow, but all of these studies are hardly comparable: they administer assorted drugs, use different forms of administration, the times of measurements differ, and some studies observe women with preeclampsia or intrauterine growth retardation.

In Tanta University 2007, in the radiology department, a study was done on 50 pregnant females 10 are normal as a control group and 40 with mild preeclampsia. The second group was divided into 2 subgroups, 10 pregnant females received the expectant management and 30 females received nitroderm patch changed every 24 hours. By studying fetal wellbeing. AFI, Doppler study of uterine, umbilical and fetal middle cerebral arteries S/D ratio and RI every 2 weeks. It was found that nitroderm patch improved maternal disease control, AFI, uteroplacental and fetoplacental circulation with reduction of mean gestational age at the time of onset of labor (Dawoud, et al). ${ }^{14}$

Twenty-five pregnant women who received GTN patches (Nitroderm TTS 10) with a dosage of $0.8 \mathrm{mg} / \mathrm{h}$, because of risk for preterm delivery, were included in a prospective study. Doppler measurements (resistance index, RI) of the umbilical artery (UA), the middle cerebral artery (MCA) and the uterine arteries of the placental (UTA-P) and the non-placental (UTA-NP) side. Calculation of the mean-RI (UTA-mean), were performed before and after 24, 48 and $72 \mathrm{~h}$ of the $1 \mathrm{st}$ GTN application. Results showed a reduction in uterine vascular impendence in cases of severe preeclampsia with primary higher resistance (Khaler, et al). ${ }^{15}$

A prospective study on 30 singleton pregnancies with severe preeclampsia and abnormal uterine and umbilical artery Doppler waveforms between 24 and 31 weeks after administration of transdermal nitroglycerin (GTN) patch (average dose $0.4 \mathrm{mg} / \mathrm{h}$ ) for 3 days. They recorded significant reduction in the maternal arterial blood pressure with a significant decrease in the PI and RI of the uterine $(\mathrm{P}<0.001)$ and umbilical $(\mathrm{P}<0.001)$ arteries if compared with the first day, before patch application. No significant change in the PI and RI of the in the middle cerebral artery $(\mathrm{P}<0.005)$. (Trapani, et al). ${ }^{16}$

Another prospective, randomized, placebo-controlled, double-blinded study was performed on 111 women who presented with abnormal placental perfusion at 19-24 weeks of gestation identified by abnormal uterine artery Doppler at mid-trimester pregnancy using Nitric oxide (NO)-donors like Pentaeritheryl-tetranitrate (PETN). Pentaeritheryl-tetranitrate significantly decreased the risk for IUGR and/or perinatal death, and preterm birth before 32 weeks was also reduced, but not the risk for PE. No placental abruption occurred in the PETN, but five occurred in the placebo group. These suggest that secondary prophylaxis of adverse pregnancy outcome might be feasible in pregnancies exhibiting abnormal placentation using PETN (Schleussner et al). ${ }^{17}$ In present study, the decrease in uterine and umbilical artery PI was 
evident this may be due to the larger sample size (43 patients). Interestingly, khaler, et al demonstrated that transdermal GTN did not affect umbilical artery Doppler indices in normal patients without pre-eclampsia, whereas Grunewald et al Demonstrated that the decrease in the PI of the umbilical artery was more pronounced in patients who already had abnormal Doppler waveforms before the initiation of therapy, as was the case in present study. ${ }^{15,18}$ Grunewald et al. hypothesized that women with endothelial dysfunction may need a smaller endothelial concentration of nitric oxide for the same response as healthy women. ${ }^{18}$ Other investigators demonstrated that the umbilical artery is less sensitive to endothelium-derived relaxing factor than are the chorionic plate arteries. ${ }^{19}$ According to previous studies, the PI and the RI of the middle cerebral artery remained unaltered following GTN administration, indicating that the fetal cerebral arterial vascular resistence is not dependent on external nitric oxide supply. ${ }^{15}$ When fetal hypoxemia occurs, there is a decrease in cerebral vascular resistance as a defense mechanism. ${ }^{20}$ As GTN improves uterine and umbilical blood flow, a decrease in the compensatory central vasodilatation could be expected. Authors speculate that the improvement in uterine and umbilical blood flow was not sufficient to reverse the brain-sparing effect during the study period. GTN caused a significant decrease in the MAP, Similar results were demonstrated with intravenous, and transdermal use. None of the patients had severe hypotension or tachycardia in this study. It remains to be determined whether or not transdermal GTN could be used in association with other drugs to control arterial pressure in patients with pre-eclampsia. ${ }^{21-23}$ Headache was the most common side effect, observed in $75 \%$ of the patients, a figure similar to that reported by other investigators. ${ }^{15,16,21}$ Headaches were well controlled with common analgesics and disappeared or decreased with adaptation to the medication. In some cases, dose reduction was necessary. Only two cases required interruption of treatment.

\section{CONCLUSION}

Nitroderm patch (nitric oxide donors) may be used as initial therapy in cases of severe preeclampsia complicated by placental insufficiency in the form of abnormal Doppler indices as present study showed the role of GTN in improving the utero-placental and fetoplacental blood flow and control of maternal blood pressure. There is no recorded major adverse effect for the mother or the fetus except headache which is well controlled by analgesics in the form of paracetamol and tolerance to the drug which could be overcome by using the patch for 16 hours and allow for 8 hours free from the drug.

Funding: No funding sources Conflict of interest: None declared

Ethical approval: This study was approved by research ethics committee, quality assurance unit at the faculty of medicine Tanta university Approval code 31561/2017

\section{REFERENCES}

1. Abalos E, Cuesta C, Grosso AL, Chou D, Say L. Global and regional estimates of preeclampsia and eclampsia: a systematic review. Eur J Obstet Gynecol Reprod Biol. 2013; 170(1): 1-7. .

2. Ducat A, Doridot L, Calicchio R, Méhats C, Vilotte JL, Castille J, Barbaux S, et al: Endothelial cell dysfunction in the STOX1 model of preeclampsia. Sci Rep. 2016;6:19196.

3. Tuzcu ZB, Asicioglu E, Sunbul M, Ozben B, Arikan $\mathrm{H}$, Koc M. Circulating endothelial cell number and markers of endothelial dysfunction in previously preeclamptic women. Am J Obstet Gynecol. 2015; 213(4):533.

4. Orabona R, Sciatti E, Vizzardi E, Bonadei I, Valcamonico A, Metra $M$ et al: Endothelial dysfunction and vascular stiffness in women with a previous pregnancy complicated by early or late preeclampsia. Ultrasound Obstet Gynecol. 2017;49(1): 116-23.

5. Sakar MN, Atay AE, Demir S, Bakir VL, Demir B, Balsak D, et al: Association of endothelial nitric oxide synthase gene G894T polymorphism and serum nitric oxide levels in patients with preeclampsia and gestational hypertension. J Matern Fetal Neonatal Med. 2015;28(16):1907-11.

6. Zawiejska A, Wender-Ozegowska E, Iciek R, Brazert J. Concentrations of endothelial nitric oxide synthase, angiotensin-converting enzyme, vascular endothelial growth factor and placental growth factor in maternal blood and maternal metabolic status in pregnancy complicated by hypertensive disorders. J Hum Hypertens. 2014;28(11):670-6.

7. Du L, He F, Kuang L, Tang W, Li Y, Chen D. eNOS/iNOS and endoplasmic reticulum stressinduced apoptosis in the placentas of patients with preeclampsia. J Hum Hypertens. 2017;31(1):49.

8. Bhavina K, Radhika J, Pandian SS. VEGF and eNOS expression in umbilical cord from pregnancy complicated by hypertensive disorder with different severity. BioMed research international. 2014;2014.

9. Johal T, Lees CC, Everett TR, Wilkinson IB. The nitric oxide pathway and possible therapeutic options in pre-eclampsia. $\mathrm{Br} \mathrm{J}$ Clin Pharmacol. 2014;78(2):244-57.

10. Hashimoto S, Kobayashi A: Clinical pharmacokinetics and pharmacodynamics of glyceryl trinitrate and its metabolites Clin Pharmacokinetics 2003;42(3):205-21.

11. Abdel Razik M, El-Berry S, Abosereah M, Edris Y, Sharafeldeen A. Prophylactic treatment for preeclampsia in high-risk teenage primigravidae with nitric oxide donors. J Matern Fetal Neonatal Med 2015; 16: 2617-2620.

12. Coleman MA, McCowan LM, North RA: Midtrimester artery Doppler screening as a predictor of adverse pregnancy outcome in high-risk women. Ultrasound Obstet Gynecol. 2000;15(1):7-12. 
13. Arduini D, Rizzo G, Normal values of pulsatility index from fetal vessels: a cross-sectional study on 1556 healthy fetuses. J Perinat Med.1990;18(3):16572.

14. Dawoud MF, Salm, Said AF. Maternal and fetal evaluation in patients with preeclampsia managed by nitroglycerine transdermal patch. Tanta Med Sci J. 2007;2:240-53.

15. Kähler C, Schleußner E, Möller A, Seewald HJ. Nitric oxide donors: effects on fetoplacental blood flow. Europe J bstet Gynecol Reproduct Biol. 2004;115(1):10-4.

16. Trapani A, Gonçalves LF, Pires MD. Transdermal nitroglycerin in patients with severe pre-eclampsia with placental insufficiency: effect on uterine, umbilical and fetal middle cerebral artery resistance indices. Ultrasound Obstet Gynecol. 2011;38(4):38994.

17. Schleussner E, Lehmann T, Kähler C, Schneider U, Schlembach D, Groten T. Impact of nitric oxide donors pentaerythrityl-tetranitrate on perinatal outcome in risk pregnancies: a prospective randomised double blinded trial. J Perinat Med 2014.;42(4):507-14.

18. Grunewald C, Kublickas M, Carlström K, Lunell $\mathrm{NO}$, Nisell $\mathrm{H}$. Effects of nitroglycerin on the uterine and umbilical circulation in severe preeclampsia. Obstet Gynecol. 1995;86(4):600-4.

19. Chaudhuri G, Buga GM, Gold ME, Wood KS, Ignarro JL. Characterization and actions of human umbilical endotheliumderived relaxing factor. $\mathrm{Br} \mathrm{J}$ Pharmacol. 1991;102(2):331-6.

20. Baschat AA, Gembruch U. The cerebroplacental Doppler ratio revisited. Ultrasound Obstet Gynecol 2003;21(2):124-7.

21. Cetin A, Yurtcu N, Guvenal T, Imir AG, Duran B, Cetin M. The effect of glyceryl trinitrate on hypertension in women with severe preeclampsia, HELLP syndrome, and eclampsia. Hypertens Pregnancy. 2004;23(1):37-46.

22. Manzur-Verástegui S, Mandeville PB, GordilloMoscoso A, Hernández-Sierra JF, RodríguezMartínez M. Efficacy of nitroglycerine infusion versus sublingual nifedipine in severe preeclampsia: a randomized, triple-blind, controlled trial. Clin Exp Pharmacol Physiol. 2008;35(5-6):580-5.

23. Cacciatore B, Halmesmäki E, Kaaja R, Teramo K, Ylikorkala O. Effects of transdermal nitroglycerin on impedance to flow in the uterine, umbilical, and fetal middle cerebral arteries in pregnancies complicated by preeclampsia and intrauterine growth retardation. Am J Obstet Gynecol. 1998;179(1):140-5.

Cite this article as: El-Ebshehy ES, Hagras AM, Elbadry AT, Awara AM. Effect of transdermal nitroglycerin patch on severe preeclamptic women with abnormal Doppler indices. Int J Reprod Contracept Obstet Gynecol 2019;8:597-603. 